\title{
EL VÍDEO INDÍGENA EN LA COMUNIDAD EMBERA CHAMÍ. Nuevas estéticas y sistemas de circulación
}

Camilo Cruz Sandoval *

DOI: https://doi.org/10.33571/revistaluciernaga.v11n22a4

\section{Resumen:}

El texto es un análisis visual sobre varios videos de dos grupos de música del resguardo Emberá Chamí del municipio de Pueblo Rico Risaralda, Bidika y lbanafarag, estos grupos cuentan con características especiales en su concepción que logran permear en sus canciones, en la construcción estética del video y que reflejan una realidad social que ha impactado tanto a su comunidad como a otros grupos sociales que han sido partícipes y a la vez víctimas del conflicto armado en Colombia, estas reflexiones sobre la estética, la composición y la denuncia social de la situación de los pueblos indígenas en Colombia es posible gracias a la apropiación que los miembros de estos grupos han hecho de las cámaras de video y circulación de su producción en Internet.

Palabras Clave: video Indígena; estética audiovisual; Emberá Chamí; apropiación; tecnologías de la comunicación y la Información; desplazamiento; resistencia.

Recibido. Julio 02, $2018 \quad$ Aceptado. Abril 23, 2019 


\section{THE INDIGENOUS VIDEO IN THE EMBERA CHAMÍ COMMUNITY. New aesthetics and circulation systems}

Camilo Cruz Sandoval*

DOI: https://doi.org/10.33571/revistaluciernaga.v11n22a4

\section{Abstract}

This text is a visual analysis of several videos by two music groups from the Emberá Chamí reservation in the municipality of Pueblo Rico Risaralda, Bidika and Ibanafarag. These groups have special features in their conception that permeate their songs, in the aesthetic construction of the video which reflects a social reality that has impacted both, their community and other social groups that have made part and victims of the armed conflict in Colombia. These reflections on the aesthetics, composition and social report on indigenous peoples' situation in Colombia, has been possible thanks to the appropriation these group members made about video-cameras, and the circulation of their production on the Internet.

Key words: Emberá Chamí; indigenous video; indigenous communication; appropriation; communication and information technologies; migration; resistance; aesthetics.

Received. July 2, $2018 \quad$ Accepted. April 23, 2019 


\section{O VÍDEO INDÍGENA NA COMUNIDADE EMBERA CHAMÍ. Novos sistemas de estética e circulação}

Camilo Cruz Sandoval*

Doi: https://doi.org/10.33571/revistaluciernaga.v11n22a4

\section{Resumo}

O texto é uma análise visual de vários vídeos de dois grupos musicais da reserva Emberá Chamí no município de Pueblo Rico Risaralda, Bidika e Ibanafarag. Estes grupos têm características especiais em sua concepção que conseguem permear suas canções, na construção estética do vídeo e que refletem uma realidade social que tem impactado tanto sua comunidade como outros grupos sociais que têm sido participantes e ao mesmo tempo vítimas do conflito armado na Colômbia, Estas reflexões sobre a estética, composição e denúncia social da situação dos povos indígenas na Colômbia são possíveis graças à apropriação pelos membros destes grupos de câmaras de vídeo e à circulação da sua produção na Internet.

Palavras chave: Emberá Chamí ; vídeo indígena; comunicação indígena;; apropriação; tecnologias da comunicação e informação; deslocamento; resistência; estética.

Recebido. Julho 02, $2018 \quad$ Aceitado. Abril 23, 2019 


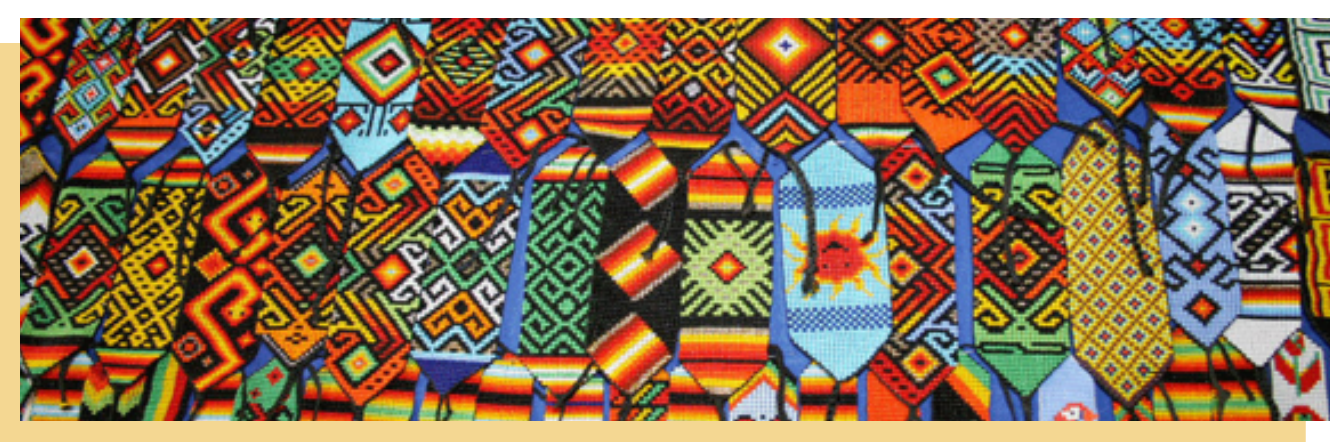

\section{Introducción}

Inicio este artículo con la reseña del libro Pueblos Expuestos, Pueblos Figurantes (2014), de Didi-Huberman. Me alineo con este pensamiento en el que se enmarca mi interés con este artículo. Él se interroga sobre la manera en que se representa a los pueblos: cuestión indisolublemente estética y política.

[Didi-Huberman] "Hoy los pueblos parecen más expuestos que nunca.

Están, en realidad, subexpuestos en la sombra de sus puestas bajo la censura o -con un resultado de invisibilidad equivalente- sobreexpuestos en la luz artificial de sus puestas en espectáculo.

En una palabra, están, como ocurre con demasiada frecuencia, expuestos a desaparecer....

Reseña. Pueblos Expuestos, Pueblos Figurantes (2014)

Caminando por las principales calles del Centro Histórico de Bogotá, Raúl el líder indígena con el que me entrevistaba me invita a pasar a su oficina en la Organización Nacional Indígena (ONIC). Fachada antigua y amoblamiento de bajo presupuesto. La casa colonial de finales del siglo XIX alberga a los representantes de las 102 comunidades indígenas [1] que habitan el territorio Colombiano, entre ellas los Emberá Chamí los cuales tradicionalmente han seguido un esquema de poblamiento disperso a lo largo de 6 departamentos de Colombia: Antioquia, Caldas, Risaralda, Chocó, Quindío y Valle del Cauca; siendo en su mayoría semi nómadas y asentándose en zonas de difícil acceso a causa de diferentes fenómenos de desplazamiento que reflejan en diversas épocas la realidad del país.

El término emberá hace alusión a ser humano o hombre. Emberá Chamí quiere decir "Habitante de Montaña". Cuando se conmemoró los 500 años del descubrimiento de América, en 1992, el Banco de la República de Colombia emitió una edición conmemorativa del billete de 10.000 pesos en el que la efigie del anverso era una mujer embera. El billete fue recogido en 1994 [2] .

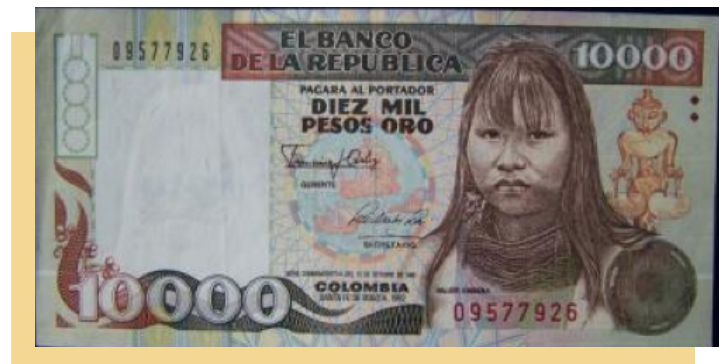

Billete de 10.000 pesos colombianos. Conmemorativo de los 500 años del descubrimiento de América

El objetivo con el que me entreviste con Raúl fue entablar un diálogo en cuanto al uso de las Tecnologías de la información y la comunicación (TIC) en su comunidad, dado el creciente impacto que han hecho estas en su cotidianidad y la reciente llegada de los programas gubernamentales que buscan brindar acceso a distintas tecnologías y sobre todo brindar conexión a internet como parte del plan educativo. Enfrentándose a esto, de manera consciente o inconsciente la comunidad se encuentra adelantando 
procesos de apropiación y entendiendo la manera en que las TIC pueden fortalecer o impactar su cultura.

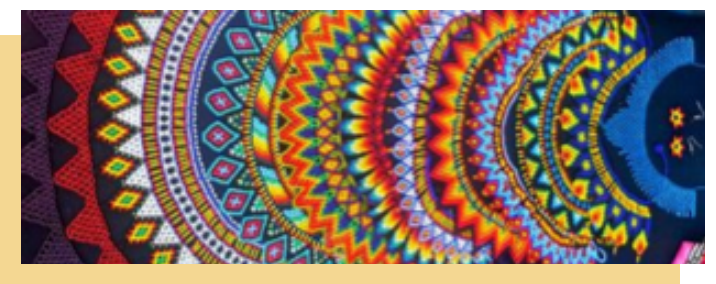

En la entrevista llegamos a un momento en donde le pregunto por los grupos musicales de la comunidad, Raúl me explica que existen varios grupos y que han empezado a grabar sus canciones en su lengua original, que es un proceso autodidacta y que poco a poco se van presentando en diversos eventos públicos dentro de la comunidad, y que además ya existen algunos videos en YouTube a los que puedo acceder. Dice Raúl:

"ellos hacen la grabación para mostrar que han recurrido a la tecnología nueva, ahí consiguen cualquier videocámara que puedan grabar, entonces ellos tratan de imitar a los grandes medios."

Para Pablo Mora (2013) los videos indígenas se presentan en un contexto de "cambio de las actitudes individuales y colectivas de la sociedad colombiana por la cuestión indígena, que van del desprecio absoluto a la admiración relativa."[3]. Para Belting (2007), el video es el medio por el cual las imágenes de la comunidad encuentran su corporeidad.

La naturaleza de este tipo de documento en movimiento, permite que nos remitamos al pasado y a la vez interpelarnos en el presente, es decir que esta producción audiovisual conservan en su interior fragmentos del pasado que de una u otra forma viajan al presente para dar elementos a la conformación de memorias colectivas, de esta manera, al observar estas creaciones audiovisuales no solo estamos viendo un reflejo de la cultura Embera Chamí o una expresión cultural, estas también nos delatan los valores de quienes las crearon, manipularon y consumieron, tal y como nos señala Moxey (2009), en tal sentido la producción de video es una práctica cultural, que también podría adquirir un sentido político.

Así lo evidencia la Muestra de Cine y Video Indígena de Colombia, Daupará, desde donde se expresan y exhiben las narrativas de los pueblos indígenas de este país:

Nasa, Misak, Pastos, Awá, Quillasinga, Inga, Kamentsä, Arhuaco, Kogui, Wiwa, Kankuamo, Wayúu, Zenú, Emberá Dovida, Embera Katío, Emberá Chamí, Kofán, Uitoto, Siona, Bora, Muinane, Tikuna, Cubeo, Barasana, Tatuyo, Makuna, Andakí, Chimila, Pijao, Kichwas, Mokaná, Muisca, Yeral, Yaruro, Coreguaje, Masiware, Siona, Tubú, Sikuani, Sáliva, Piapoco y Kuna Tule.

Daupará en el año 2009, realizó el primer intercambio de saberes de comunicadores indígenas y no indígenas, lo cual generó un escenario intercultural de diálogo y debate frente a las formas de "representación" de lo indígena en el audiovisual. En el 2010, abordaron los temas de la mujer indígena y la comunicación así como la academia y la comunicación indígena. En el 2011, empezaron a ligar y tejer memoria con el territorio, realizaron una muestra itinerante a los cabildos Misak -Misak, Inga, Pastos, Nasa y Yanacona de Bogotá.

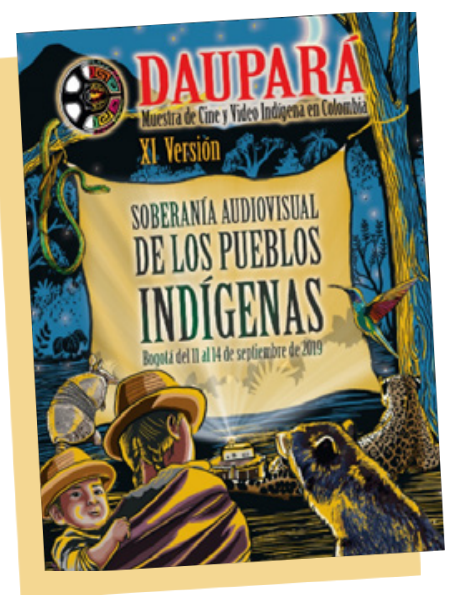

En el año 2012, Daupará, con el lema "Putchi eiyatulu akuaipaa, del Wayuunaiki que traduce al español: Imágenes y palabras para contar y construir se 
enfocaron en la protección y la paz. En el 2013, bordaron las políticas públicas, las reivindicaciones y el afianzamiento de las formas propias de comunicación. En el año 2014, el tema fue la problemática ambiental local. En 2015, con el lema "renaciendo en Bakatá" se enfocaron en la memoria y el patrimonio cultural. En el 2017 su tema fue "de regreso al vientre" , en el 2018 "con los espíritus de la imagen" y en el 2019 "Soberanía Audiovisual de los pueblos indígenas". Disponible en https:// daupara.org/contexto-historico/.

En este artículo se presentan tres escenas de análisis de los artefactos audiovisuales (Moxey; 2009) [4] producidos por las agrupaciones musicales [5] Bidika y Ibanafarag de la comunidad Emberá Chamí, y el usos de sus producciones en los contextos de enunciación. En la primera escena se registra los diferentes aspectos de la producción y realización de los videos de estas agrupaciones; la segunda se enfoca en la circulación y consumo de dicha producción y en la tercera nos referimos a la construcción social que configura lo que podría denominarse una lógica de resistencia.

\section{El audiovisual indígena dentro de la comunidad Emberá Chamí}

Al consultar los videos que hacían referencia a la comunidad Emberá Chamí me encontré con varios referentes que lograron captar mi atención por su singular manera de mostrar, tanto a los miembros de la comunidad indígena como su contexto y su realidad, generando en mí la inquietud sobre la importancia y la trascendencia del audiovisual indígena dentro de la comunidad Emberá Chamí.

Inicialmente hay que decir que en Colombia el audiovisual indígena [6] se ha posicionado a lo largo del tiempo desde diferentes frentes. En un principio producido por la iglesia católica, sirvió como manera de presentar de una forma "exótica" a las comunidades en países de primer mundo. Es el caso del primer audiovisual en el que se registran indígenas, titulado "Expedición al Caquetá" que data del año 1.930.

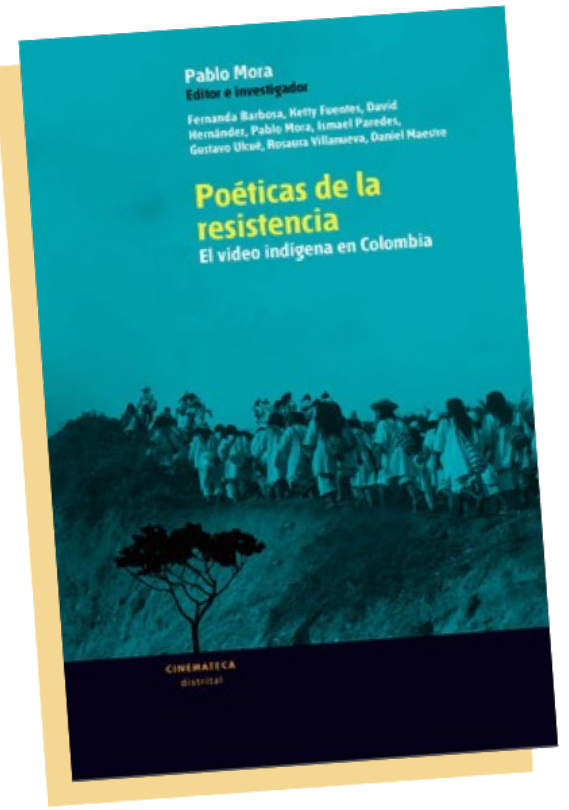

En el libro"Poéticas de la resistencia. El video indígena en Colombia" (2012). Pablo Mora, y otros investigadores que hacen parte de estos pueblos y que participan en movimientos de reivindicación de las nacionalidades indígenas [7], retrataron en esta publicación el proceso que ha llevado a las comunidades indígenas de Colombia a expresarse a través de imágenes en movimiento. Registra además una serie de valiosas obras en términos políticos y de recuperación de sus identidades perdidas.

El texto recorre la historia del cine con presencia indígena, desde la evangelizadora Expedición al Caquetá en 1930, hasta la actual representación del indígena en lo audiovisual [8].

Poco a poco las comunidades indígenas se han empoderado de cámaras para auto representarse, alejándose de las visiones externas y reflejando sus culturas desde adentro. A lo largo de ese proceso, también se han documentado las denuncias frente a los atropellos que han sufrido las comunidades indígenas en este País. 
Acerca de la comunidad Emberá se han realizado varios documentales [9] que podrían incluirse a la categoría de audiovisual indígena, en estos se denuncia los conflictos entre la comunidad y los misioneros católicos que trataban de evangelizarlos a como diera lugar, lo que se puede apreciar en el documental "Emberá: The End of The Road" (Emberá: el fin del camino), realizado en 1971.

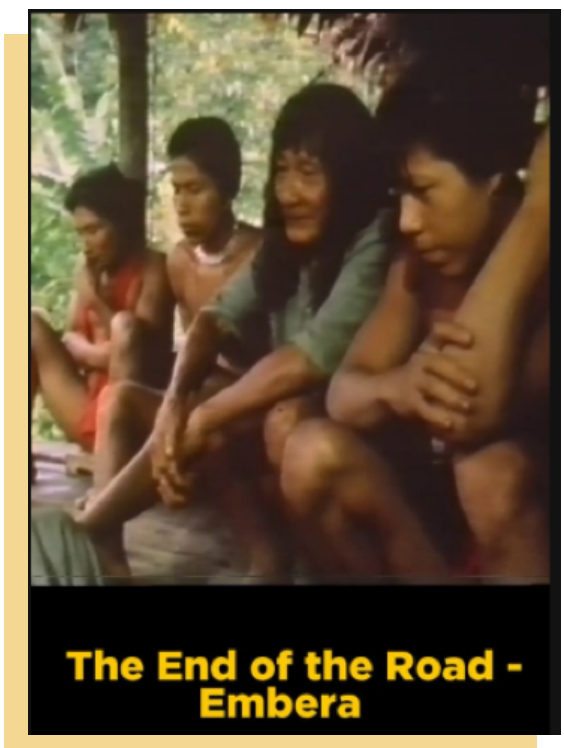

Otra temática que se observa en los documentales indígenas es el conflicto de tierras entre estos y los Capunia [10] quienes le han usurpado sus tierras obligándolos a desplazarse a otros territorios. En "Civilización y Supervivencia" (1980), Jesús Mesa García, realizador de este documental, en la sipnosis de este producto visual indica:

Las comunidades indígenas, han procurado mantener, conservar, a toda costa, sus tradiciones, su lengua, sus mitos, su folclor. El indígena nuestro, espera comprensión y que sus compatriotas, más que todo las autoridades, respeten y hagan respetar sus derechos. [11]

En los films "Los Embera" (1985) y "El Autodescubrimiento" (1991) se registran los rituales, mitos y la vida cotidiana de esta comunidad, además de problemas sociales y económicos tales como la falta de servicios públicos, la deficiente cobertura de salud, imposición de una educación que no reconoce su lengua ni sus tradiciones. En el video, "Promesas incumplidas" (2015) se evidencian los incumplimientos por parte del gobierno nacional en cuanto a la restitución de derechos territoriales de los pueblos indígenas.

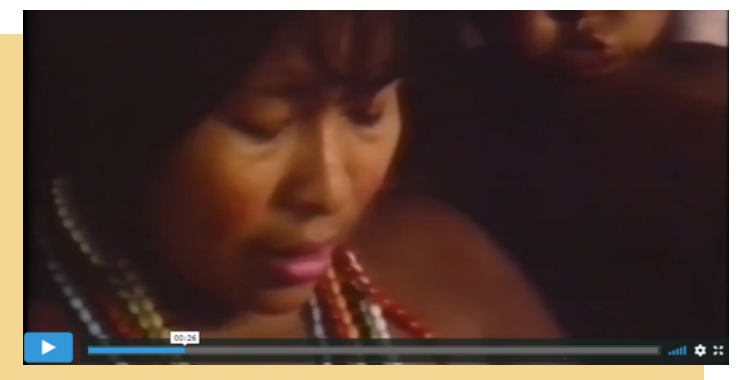

https://vimeo.com/ondemand/theendoftheroadembera

Estas producciones, a pesar de construir un imaginario sobre la comunidad Embera no corresponde a las voces propias de los integrantes de la comunidad puesto que son producciones externas dirigidas por antropólogos y realizadores audiovisuales que imprimen su visión de la comunidad e interpretan lo que logran ver en su mundo. Desde la perspectiva de Hans Belting: "La incertidumbre acerca de sí mismo genera en el ser humano la propensión a verse como otros" [12]

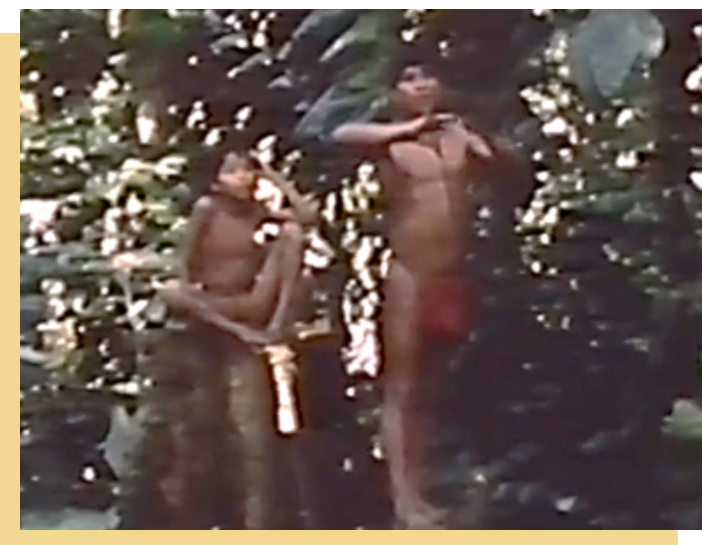

https://vimeo.com/ondemand/theendoftheroadembera

Con devenir de los años y el acceso a nuevas tecnologías de comunicación, los indígenas han sentido la necesidad de capturar sus propias imágenes sobre sí mismos, aún falta más consciencia y por supuesto recursos tecnológicos. 
2. Bidika y Ibanafarag: Dos maneras de cantarle al resguardo.

Bidika, es una agrupación perteneciente a la comunidad de Kundumi, la integran 10 miembros todos pertenecientes a la comunidad Emberá Chamí. La creó Virgilio Guatiqui, en el año 2009; él aprendió de manera autodidacta a tocar los instrumentos y enseñó a los demás. En el año 2010, Virgilio fue asesinado por un grupo armado dentro del resguardo. Un año después Bidika grabó un CD con 8 canciones entre las que se encuentra un homenaje a su fundador.

Imagen 1.

Grupo Bidika - Locación: Comunidad Kundumi

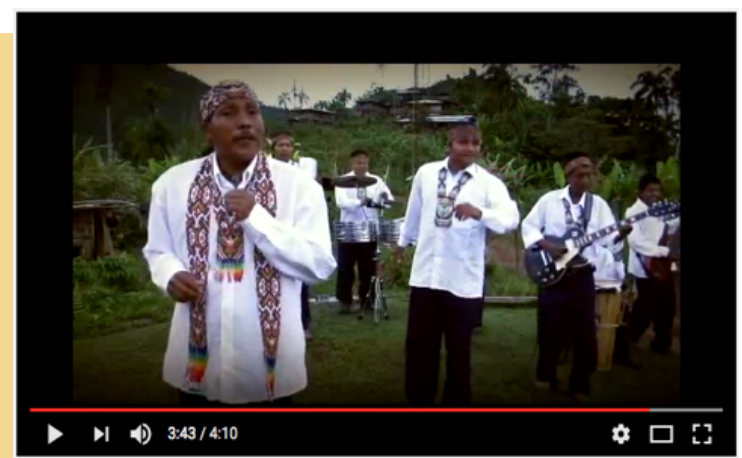

Bidika-Padachuma (Autor: Alejandro Gonzàlez Tascòn) (Embera Chamí)

Disponible en: https://www.youtube.com/ watch? $v=n D f Y e c x D 3 F E$

Ibanafarag, se reconoce como parte de la comunidad de Dokabu, está conformada por 6 integrantes y fue fundada en la ciudad de Bogotá por miembros de diferentes comunidades que fueron desplazados, por grupos armados, del Resguardo Unificado Emberá Chamí. Aprendieron de manera autodidacta a tocar los instrumentos y esta habilidad fue su sustento diario en las calles durante varios años hasta que lograron regresar a su cabildo y asentarse en la comunidad de Dokabu, esto fue posible gracias a la ley de víctimas y restitución de tierras [13]
Imagen 2.

Grupo musical Ibanafarag - Locación: Bogotá

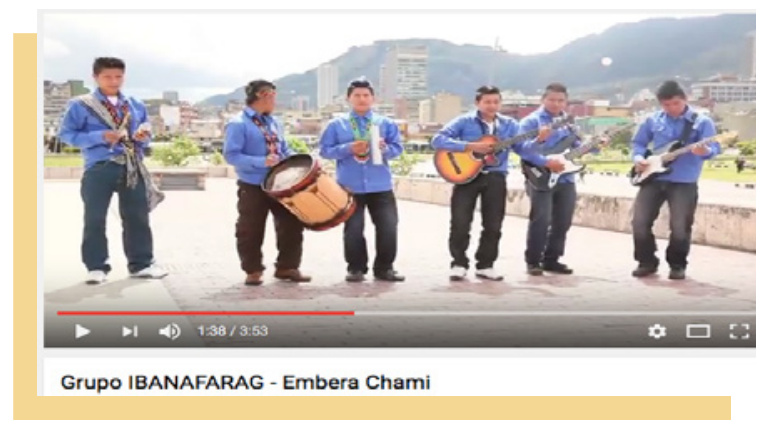

Tomada de: https://www.youtube.com/ watch?v=saP1 $\mathrm{mp}-\mathrm{md} 4 \mathrm{c}$

En el Resguardo Unificado Embera Chamí y sus 21 comunidades, se evidencia una reciente tendencia a la conformación de grupos musicales que suplen las necesidades de entretenimiento del resguardo, estos grupos inscriben sus composiciones en una variación del género parrandero.[14] Dicho género musical es de origen antioqueño que llegó a la comunidad Emberá Chamí a través de la colonización cultural paisa y principalmente a través de la radio, medio de comunicación masivo de gran impacto en esta comunidad. [15]

Este género se puede clasificar como una mezcla entre ritmos caribeños, andinos, campesinos y la trova paisa. Tuvo su origen en los años 30 en el proceso de industrialización de Antioquia y se escucha en las celebraciones decembrinas de cada año. Los grupos musicales Emberá, simplifican el género "parrandero" de tal manera que su interpretación no demande mayor pericia, ni gran cantidad de instrumentos y se adapte de alguna manera a las condiciones de desplazamiento del resguardo, dado que en su mayoría, las comunidades están en colinas empinadas y para llegar a ellas hay que hacer extensos recorridos, por lo que movilizar muchos instrumentos no es muy viable. 


\subsection{Las imágenes}

Las imágenes presentadas corresponden a dos capturas de video de YouTube en las que se presenta la puesta en escena de las dos agrupaciones analizadas, a través de estas podremos evidenciar varios aspectos.

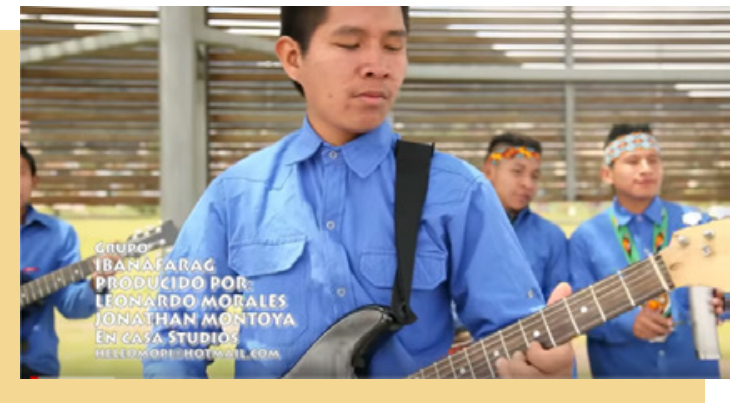

Tomado de: https://www.youtube.com/ watch? $=$ saP1 $\mathrm{mp}-\mathrm{md} 4 \mathrm{c}$

En la imagen 2. [16] se observa al grupo Ibanafarag en una producción realizada en la ciudad de Bogotá. El paisaje que se evidencia es urbano, rodeado de edificios y construcciones; lo que es recurrente en la mayoría de sus producciones. Este paisaje citadino es el que acoge a los indígenas migrantes en Colombia. Contexto en los que en la mayoría de los casos estos migrantes están obligados a vivir en condiciones infrahumanas a causa de la incapacidad del gobierno por asistir a la gran cantidad de personas desplazadas. Este factor de desplazamiento forzado es evidente en la estética y sonoridad de este grupo musical.

Su producción musical y audiovisual está construida desde la añoranza de una comunidad en la que vivieron y que extrañan, la mezcla de elementos étnicos de diferentes comunidades en su vestuario evidencian sus procesos multiculturales y de adaptación a la Urbe.

Los hombres visten ropa capunia (de no indios) y como rasgo común predomina en sus camisas el color azul, esto hace referencia directa a su nombre Ibanafarag que significa pájaro azul, aludiendo a la relación entre la capacidad de volar de las aves y el constante movimiento en el que se encuentran los indígenas desplazados por la violencia.

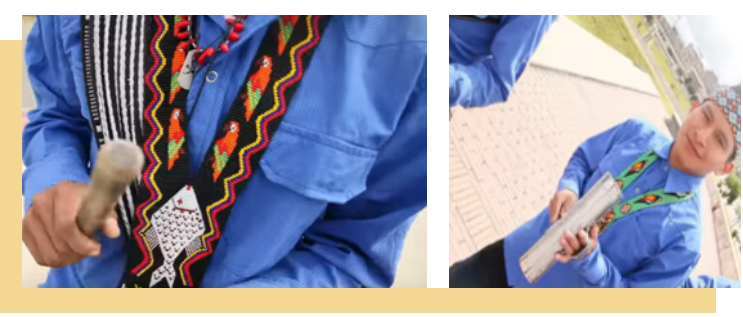

Tomada de: https://www.youtube.com/

\section{watch? $\mathrm{v}=\mathrm{saP} 1 \mathrm{mp}-\mathrm{md} 4 \mathrm{c}$}

En su estética sobresalen los collares tejidos en Chaquira Checa [17] reconocidos como tradicionales dentro de la comunidad Emberá Chamí y con el que desarrollan variadas y coloridas artesanías. Con estos las mujeres se adornan cuando danzas su música tradicional. Esos collares evocan a los diferentes animales a los que se rinde homenaje dentro de la comunidad.

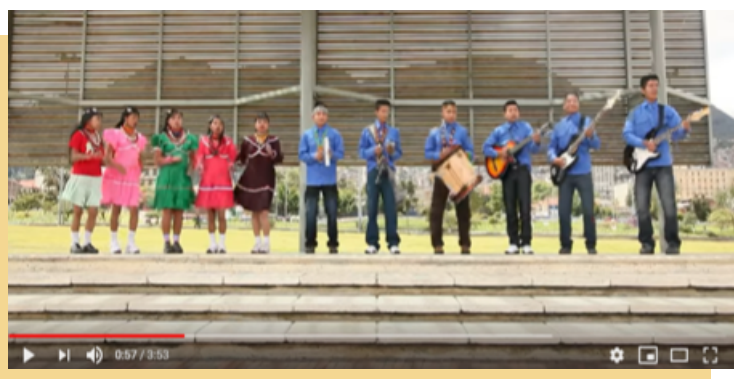

Tomada de: https://www.youtube.com/

watch?v=saP1mp-md4c

Un aspecto a resaltar es que las mujeres en la mayoría de las producciones Emberá no desarrollan un rol activo dentro de los grupos musicales, son pocos los registros en donde una mujer interpreta algún instrumento, esto al parecer refleja la posición que culturalmente tiene la mujer dentro de la comunidad, sin embargo se hace referencia constante a sus cualidades femeninas y sus rostros pintados, los cuales representan varios mitos de creación y diferencia a través del tipo de marca a las que están casadas de las solteras.

El tema de los roles de género y los elementos característicos de cada uno de ellos es un fenómeno que resulta interesante para el universo visual de la comunidad Emberá Chamí, sin embargo a través del tipo de instrumentos visuales que se abordan en este texto no es suficiente para sentar una posición frente a este aspecto, que no desmerece un estudio más profundo pero que no es el objetivo en este artículo. 
Imagen 3.

Comentarios en Youtube sobre la producción audiovisual de Ibanafarag

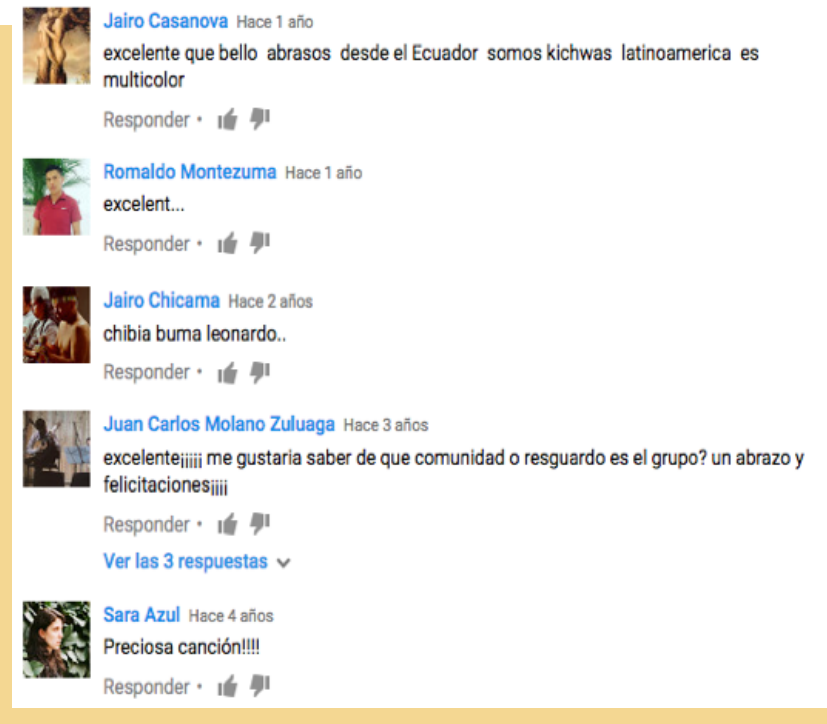

En cuanto a sus letras, están construidas en su mayoría sobre rimas fallidas y/o forzadas que básicamente se refieren a su comunidad y a su estilo de vida rural, donde se participa comunitariamente en las labores del campo y se disfruta de la tranquilidad que en el caso de este grupo musical ha sido entorpecida por el desplazamiento. Su canto dice:

"...El grupo Ibanafarag siempre estará alegre, vivimos muy felices, vivimos con respeto...

Yo vivo muy alegre mi vida cambio, y estoy muy contento por la música Emberá..

Las mujeres Emberá están muy contentas, pintando la carita, peinando el cabello...

Yo vivo muy alegre mi vida cambio, y estoy muy contento por la música Emberá..."

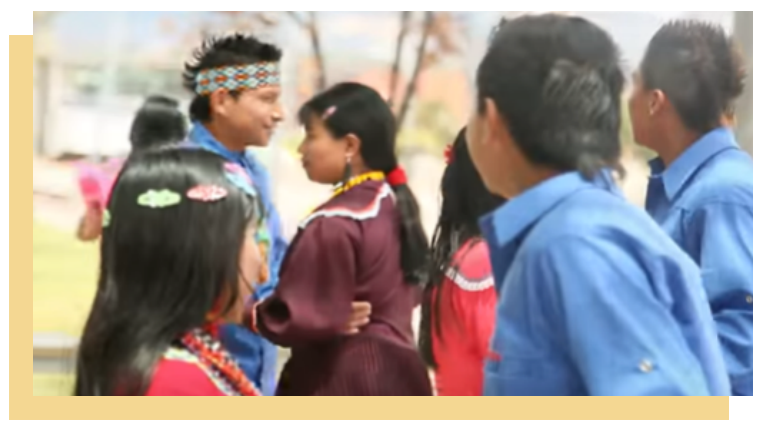

Tomada de: https://bit.ly/2KHVzYs

La modalidad de auto-representación que define las lógicas narrativas de estas producciones en particularysus características formales no es sino la expresión de una realidad compleja y cambiante de relaciones sociales específicas que han construido los pueblos indígenas en su relación con las amenazas que les vienen de afuera, o en este caso que los asecha día a día en su condición de desplazados.

Imagen 4.

Grupo musical Bidika
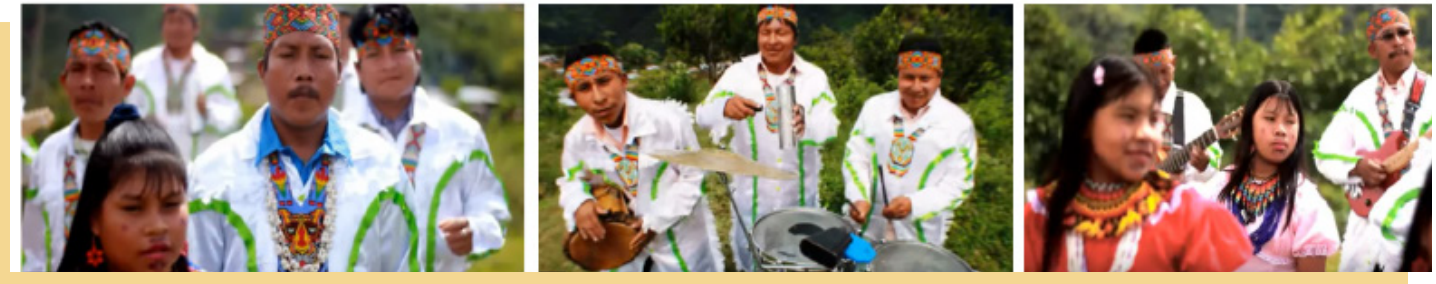

Tomado de: https://www.youtube.com/watch?v=2rw3DL2p7q8 
Las producciones audiovisuales del grupo musical Bidika en la imagen 4 . [18], se estructuran desde un contexto de enunciación rural, en donde resaltan a primera vista los colores de las artesanías en chaquira checa y las camisas [19].

Este contexto rural permitequelasnarrativas presentadas en los instrumentos visuales se construyan desde la representación directa de las labores del campo, ya no evocando como en el caso de la agrupación Ibanafarag, si no representando de manera directa los roles y personalidades de la comunidad, este factor permite que los elementos contextuales sean evidenciados de tal manera que se construya una figura más íntima sobre la cultura Emberá Chamí, resaltando sus valores y orgullos como pueblo.

Para Didi Huberman (2014), "basta con que una imagen se haga pública, se torne cosa pública para que entre en un pie de igualdad en los circuitos del derecho, los juegos del poder y el campo conflictivo de la cosa política"[20]

Esta afirmación nos permite entrar a describir de qué manera la comunidad Emberá empieza a construir sus imágenes.

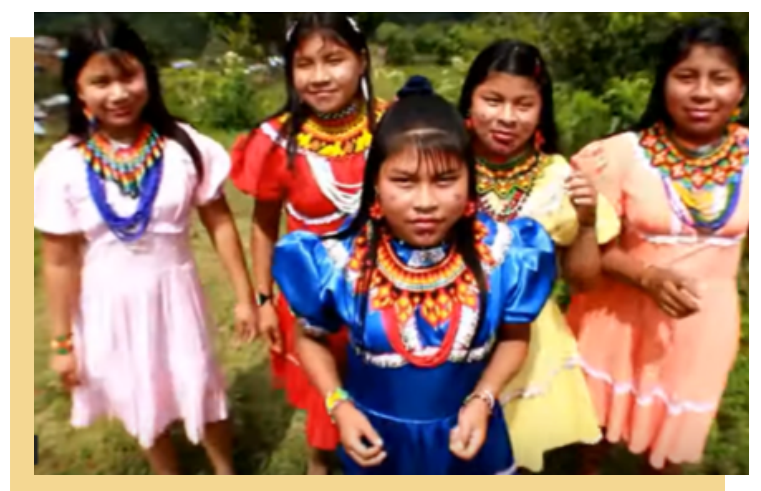

Tomado de: https://www.youtube.com/ watch?v=2rw3DL2p7q8

Aparecen en sus composiciones musicales constantes referencias a comunidades cercanas del cabildo y elementos propios de su diario vivir, así como los lugares donde se habita, el tambo [21] y los caminos que comunican con el río, se experimenta con las figuras humanas por medio de la edición y se hacen homenajes [22] a sus líderes asesinados por el conflicto armado, es común también que se tomen la libertad de adaptar canciones escuchadas en la radio al género parrandero. En una de sus canciones le cantan al resguardo, en su dialecto [23], es español se alcanza a entender:

“...Mi resguardo Emeberá Chamí, mi resguardo Emberá Chamí...[continua la canción en su legua]

Un elemento recurrente dentro de las composiciones es la relación que se encuentra entre la comunidad y las plantas, este factor se hace evidente en varios elementos, un ejemplo claro es el nombre de la agrupación Bidika, el cual es la palabra con la que denominan al arbusto con el que se cocina la mayoría de sus recetas; su vestuario (túnica blanca con una franja verde) está inspirado en este mismo arbusto.

El Badachuma [24] también hace parte importante en sus composiciones, lo que evidencia las dinámicas gastronómicas de la comunidad, en donde su uso es habitual. Dadas las condiciones geográficas donde se encuentra el resguardo, no todos los suelos permiten la cosecha, por lo que el Badachuma es de vital importancia en su dieta gracias a que fructifica de manera fácil y es nativo de esta tierra, además de sus frutos las hojas de la planta son usadas para la refrigeración de alimentos perecederos y en la mayoría de rituales de sanación realizados por el Jaibaná [25] se usan como abanicos para ahuyentar los Jai. [26]

Frente a este fenómeno de adaptación de los medios, Pablo Mora sugiere que "las creaciones indígenas son diferentes, puesto que provienen de sujetos que visibilizan desde adentro el mundo de las identidades y de los movimientos étnicos, revaluando los imaginarios de frontera a partir de prácticas de creación colectiva y colaboración intercultural que no solo aportan a la comprensión de lo étnico desde visiones endógenas sino que están modificando sustancialmente las viejas concepciones del arte, la cultura y la política". 


\subsection{Sobre los sistemas de circulación}

La producción visual actual de la comunidad Emberá Chamí transita entre varias esferas multiculturales que han influenciado a la comunidad este proceso de apropiación ha traído consigo nuevas posibilidades técnicas de realización y de tránsito de estos artefactos visuales, en relación a los que podemos decir que la circulación dentro de la comunidad se da a través de los pocos dispositivos que los miembros migrantes llevan consigo de regreso a la comunidad y se difunden de manera comunitaria. Se comparte un televisor para toda la comunidad y se reúnen en las horas de la tarde, después de la jornada de la siembra o la cosecha en un lugar en el que se congregan niños y adultos y se proyectan los videos de los grupos locales mezclados con los artistas del momento.

Además de este tipo de espacios, que se repiten en todas las comunidades del resguardo, los contenidos circulan a través de teléfonos celulares y se comparten a través de YouTube. En los centros de computo, en la cabecera municipal, los Capunias cobran una suma de dinero por subir los vídeos en dichas plataformas.

Así la comunidad tiene sus propias estrellas musicales que se legitiman a través de la pantalla y que llevan consigo los valores, sentimientos, añoranzas y problemáticas de su cultura, siendo entonces una estrategia eficazmente simbólica para representarse y llegar a los más jóvenes.
Los artefactos visuales producidos dentro de la comunidad pasan a adquirir la condición de representación y configuran lógicas de territorio y tradición a partir del cual podemos empezar a pensar el campo de lucha por la cultura y la lengua.

En cuanto a la circulación externa, al ser un contenido al que se adapta diversas manifestaciones consideradas como occidentales, tales como el ritmo y los lenguajes visuales comerciales, dichos contenidos no son tenidos en cuenta por los festivales audiovisuales indígenas. Esto requiere una reflexión más profunda sobre lo que se considera audiovisual indígena.

El debate por la categorización de los contenidos no se ha dado hasta el momento pero debe abordarse teniendo presente las adaptaciones culturales de medios capunias a las necesidades y posibilidades del pueblo Embera.

Estos artefactos visuales circulan sin categoría en la red, puesto que tampoco entran dentro de la categoría de música indígena. Categoría que por lo regular está asociada a géneros andinos tradicionales - a los interpretados con instrumentos prehispánicos y raíces fuertemente ligadas a ceremonias espirituales.

\section{Imagen 5.}

Comentarios en Youtube sobre la producción audiovisual de Bidika

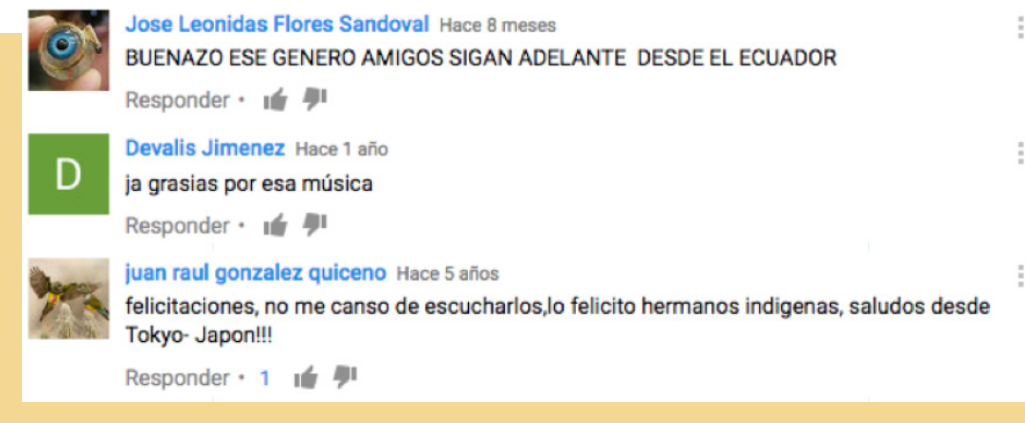

En un corto repaso por las opiniones que generan este tipo de artefactos visuales en la red, podemos hacer presente la opinión de Pablo Mora sobre el proceso de lo indígena en Colombia, en donde los espectadores de diversas partes del mundo, reivindican 
la admiración frente a las expresiones indígenas y se reconoce su cultura además de evidenciar una exaltación sobre estos artefactos visuales.

\section{Imagen 6.}

Comentarios en Youtube sobre la producción audiovisual de Bidika

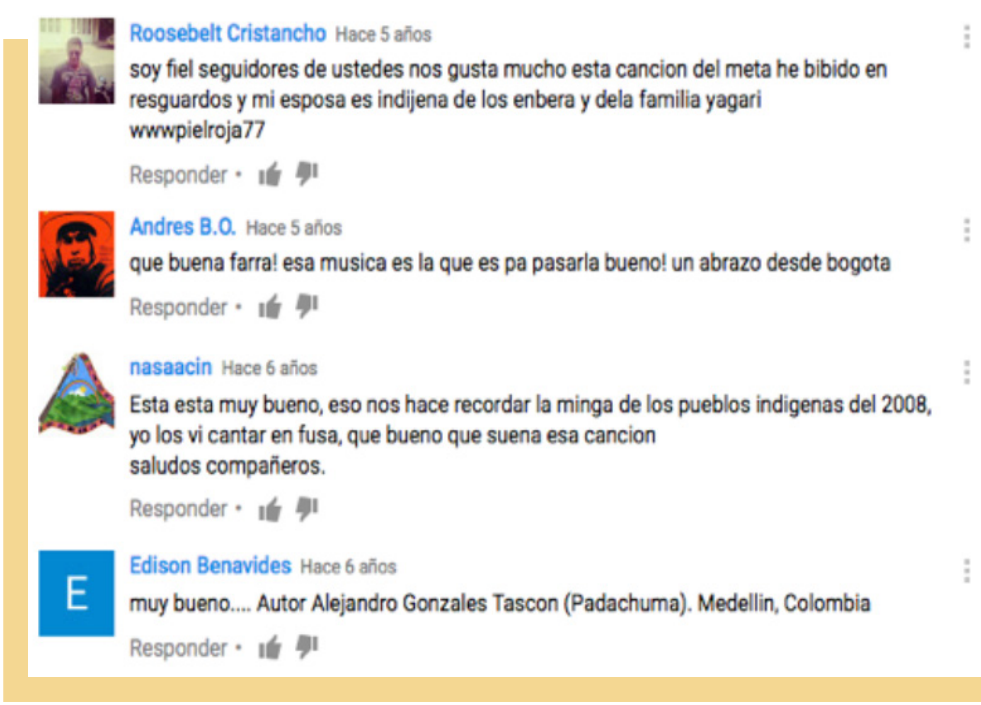

En los comentarios se alude a lo indígena y su importancia en la construcción de nación, la alegría de un pueblo y sus ancestros, se puede identificar también que este tipo de artefactos en la red cumplen una función de espacio virtual para el encuentro de diferentes etnias, pues reúne a las comunidades indígenas en torno al entretenimiento.

Imagen 6.

Comentarios en Youtube sobre la producción audiovisual de Bidika

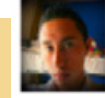

LUIS GARZON Hace 4 años

me encanta este grupo,su ritmo es fantastico ojala suenen por mucho tiempo.

Responder - It 71

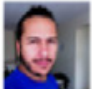

Luis Alberto Bravo Caballero Hace 4 años

A mi la verdad este video me llena de alegria, es nuestro origen es nuestra tierra.

Responder * It 7

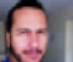

Luis Alberto Bravo Caballero Hace 4 años

Keisylio.. \#matese.

Responder * It 7

f각) victor alonso Martinez Hace 4 años

los felicito mostrando la cultura de nuestra pais, por favor saquen la letra en su idioma

Lara que lo comparta con la humanidad

Responder , It 7

\subsection{Nuevas estéticas de lo político. Imágenes de resistencia}

Como podemos ver, la comunidad Emberá ha logrado construir una serie de artefactos visuales salidos del canon artístico imperante. Como indica Guash (2003):

"Lo importante ya no es buscar el valor estético del "arte elevado», sino examinar el papel de la imagen "en la vida de la cultura»". [27] 
En otras palabras, se debe apreciar la producción audiovisual indígena, como un valor, que probablemente, no procede de sus características intrínsecas e inmanentes sino de la apreciación de su significado, tanto dentro del horizonte cultural de su producción como en el de su recepción.
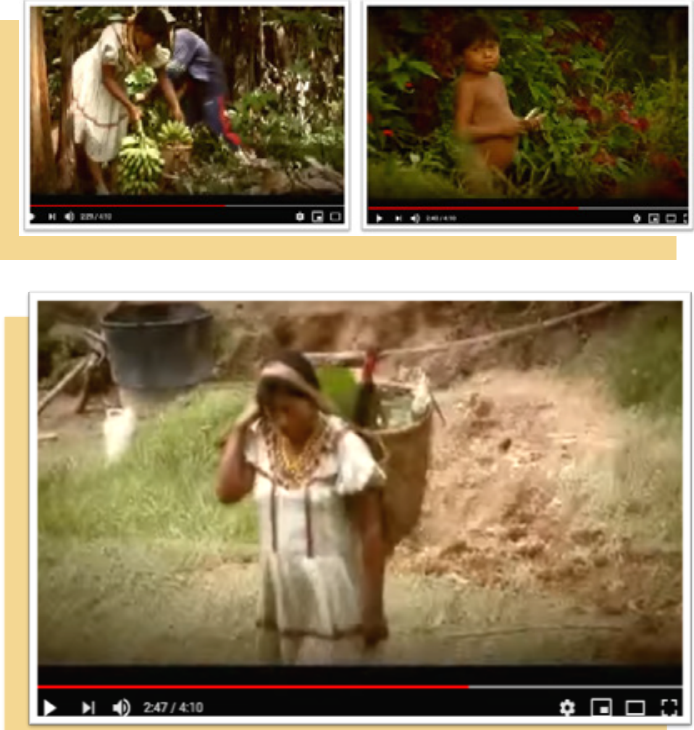

Tomado de: https://bit.ly/35hQbVg

Para James Elkins, otro teórico destacado de los estudios visuales, las imágenes privilegiadas por la descriptiva etiqueta "arte" constituyen solo una pequeña parte del mar del imaginario en el que las culturas del mundo se mueven. Puesto que más que ejercicios aislados de creación artística, estos artefactos visuales se conciben como oportunidades para desatar o fortalecer procesos de autoafirmación cultural y como estrategias para plantear utopías o deseos emancipatorios en cuestiones de soberanía, ciudadanía, modelos de desarrollo y políticas culturales.

Mirzoeff (2016) concibe los estudios visuales en términos de análisis del mensaje de los artefactos visuales más que de su medio, estando interesado por encima de todo en las funciones culturales y políticas de las imágenes en situaciones sociales. Enfoque necesario para entender estos artefactos visuales a los que nos enfrentamos, que muchas veces son excluidos por sus contenidos políticos y carecer de un "aura" artística, como lo denominaría Benjamín. Por el contrario la invitación es a girar la mirada sobre estas nuevas estéticas fuera del canon y en vez de:

"invalidar las estructuras, funciones y efectos de las obras políticas, lo que debe entenderse de ellas es que provienen de prácticas culturales presionadas por principios de autoridad y legitimidad que moldean y limitan las formas."[28]

En este caso, la apuesta por legitimar este tipo de contenidos dentro de las lógicas de producción indígena se sustenta desde la des categorización del género y la necesidad de ampliar el espectro de comprensión de tal forma que se reconozcan las narrativas implícitas en este tipo de artefactos audiovisuales como medio de lucha por medio de elementos que construyen las lógicas de la resistencia y que permiten la supervivencia de su cultura y su lengua.

\section{Conclusiones}

En general la narrativa recurrente en los videos de la agrupación lbanafarag es de extrañamiento frente a los nuevos procesos que la ciudad demanda en su diario vivir, a esto se suma el que no dominan perfectamente el idioma español.

Las producciones audiovisuales del grupo musical Bidika, se estructuran desde un contexto de enunciación rural, en donde resaltan a primera vista los colores de las artesanías en chaquira checa y las camisas. Este contexto rural permite que las narrativas presentadas en los instrumentos visuales se construyan desde la representación directa de las labores del campo, ya no evocando como en el caso de la agrupación Ibanafarag, si no representando de manera directa los roles y personalidades de la comunidad, este factor permite que los elementos contextuales sean evidenciados de tal manera que se construya una figura más íntima sobre la cultura Emberá Chamí, resaltando sus valores y orgullos como pueblo. 
Como es evidente a pesar de pertenecer a la misma comunidad y cantar en lengua Emberá Chamí, estas dos agrupaciones cuentan con espacios de enunciación diferentes y construyen sus mensajes desde narrativas particulares en las cuales se evidencian sus situaciones sociales a través de la música y haciendo uso de un género que en sus inicios es festivo pero que en este caso ha mutado a necesidades diferentes.

Los contenidos de la producción audiovisual indígena, en este caso los artefactos visuales que ya hemos revisado, no son solamente huellas en el tiempo del mundo histórico de los indígenas, tal como lo plantea la teoría convencional al analizar las funciones denotativas de los documentos audiovisuales, sino enunciados que constituyen, más que evidencias sobre la realidad, formas discursivas para interpretarla.

\section{Bibliografía}

Artículo 66. Ley de Víctimas y Restitución de Tierras, 2011.

Belting, Hans (2007). Antropología de la imagen . Argentina: Editorial Katz.

Burgos Herrera, A. (2000). La música parrandera paisa. Medellín: Editorial Lealon.

Cinemateca Distrital. (2012). Cuadernos de cine colombiano. Inventario parcial de Cine y video indígena (1930-1992) No 17A . Bogotá, Colombia: Cinemateca Distrital.

Didi-Huberman, G. (2014). Pueblos Expuestos, Pueblos Figurantes. Argentina: Ediciones Manantial.

Guasch, Anna María (2003). LOS ESTUDIOS VISUALES EN EL SIGLO 21. Un estado de la cuestión. Murcia, España:
Para concluir, la apuesta final con la que quisiera cerrar es la que invita a pensar en las imágenes que resisten a pesar de que no muestren la realidad que intentan denunciar. Puesto que como nos dice Pablo Mora. "La toma de conciencia del espectador sobre las realidades del exterminio físico y cultural de los pueblos indígenas hace de estas obras ejemplos de reflexividad política donde se desmontan imaginarios y salen a flote realidades oscurecidas, fijando potencialmente el compromiso de los espectadores con las representaciones de ese mundo histórico" que ha conseguido construir otro país a través de la toma de voz y de imágenes, de partes de otra realidad que ha permanecido oculta para la gran mayoría.

CENDEAC.

Sánchez Botero, Esther (2009). LOS PUEBLOS INDÍGENAS EN COLOMBIA Derechos, Políticas y Desafíos. Bogotá: UNICEF Colombia.

Mora Calderón, Pablo (2013). Nuestras miradas . Bogotá, Colombia: Fundación Friedrich Ebert Stiftung.

Mirzoeff, Nicolas (2016). Cómo ver el Mundo: Una Nueva Introducción a la Cultura Visual. Editorial

Paidos.

Salazar Torres, Neyder Jhoan. Comunicación Indígena en Colombia. Entre el sentido de lo propio y lo apropiado. Luciérnaga Comunicación, [S.I.], v. 8, n.15, p. 48 -62, may 2017. ISSN $2027-1557$. Disponible en: https://revistas.elpoli.edu. co/index.php/luc/article/view/886

\section{Cibergrafía}

Bidika [Alejandro Ardila]. (2011,diciembre 25). Homenaje al maestro Virgilio. Recuperado de https://www.youtube. com/watch?v=egBCudBenhw Imágenes

Imagen 1: Bidika [Alejandro Ardila].
(2009, Octubre 26). Padachuma. Recuperado de https://www.youtube. $\mathrm{com} /$ watch?v=3La208a0g7

Imagen 2: Ibanafarag [Leonardo Morales]. (2012, Junio 18). Embera Chamí. 
Recuperado de https://www.youtube. com/watch? $=$ saP1 $\mathrm{mp}-\mathrm{md} 4 \mathrm{c}$

Imagen 3: Ibanafarag [Leonardo Morales]. (2012, Junio 18). Embera Chamí. Recuperado de https://www.youtube. com/watch? $\mathrm{v}=\mathrm{saP} 1 \mathrm{mp}-\mathrm{md} 4 \mathrm{c}$

Imagen 4: Bidika [Alejandro Ardila]. (2011,diciembre 26).Pueblos Indígenas. Recuperado de https://www.youtube. $\mathrm{com} /$ watch? $\mathrm{v}=\mathrm{nz} 8 \mathrm{cfU}$ ifFqw

Imagen 5: Bidika [Alejandro Ardila]. (2009, Octubre 26). Padachuma. Recuperado de https://www.youtube. com/watch?v=3La208a0g7U

Imagen 6: Bidika [Alejandro Ardila]. (2011, Diciembre 26). Resguardo. Recuperado de https://www.youtube. $\mathrm{com} /$ watch? $\mathrm{v}=\mathrm{qq}$ lt5VrwyOo

\section{Notas}

[1] Esther Sánchez Botero. (2009). LOS PUEBLOS INDÍGENAS EN COLOMBIA Derechos, Políticas y Desafíos. Bogotá: UNICEF Colombia.

[2] Disponible en: https://es.wikipedia.org/ wiki/Ember\%C3\%A1

[3] Pablo Mora Calderón. (2013). Nuestras miradas . Bogotá, Colombia: Fundación Friedrich Ebert Stiftung.

[4] Este concepto es tomado de la propuesta de Keith Moxey en su texto "Los estudios visuales y el giro icónico".

[5] Para el desarrollo de este texto abordaremos el caso de las agrupaciones Bidika y lbanafarag, dado que son las únicas dos agrupaciones dentro del resguardo que cuentan con registro audiovisual de su trabajo, lo que permite tener un artefacto audiovisual propio para su análisis.

[6] En la delimitación del campo, se recomienda el uso de categorías de clasificación que provienen de los antropólogos como video indígena, audiovisual indígena y otras como medios indios o medios aborígenes. Sin embargo, algunos autores indígenas se niegan expresamente a considerar lo que hacen como obras y prefieren referirse a ellas como "materiales de comunicación" o simplemente videos, para este escrito se usara arbitrariamente el termino audiovisual indígena.

[7] Fernanda Barbosa, Ketty Fuentes, David Hernández, Ismael Paredes, Gustavo Ulcué, Rosaura Villanueva y Daniel Maestre.

[8] Tomado de: http://www.servindi.org/ actualidad/129358

[9] Cinemateca Distrital . (2012). Cuadernos de cine colombiano. Inventario parcial de Cine y video indígena (1930-1992) No 17A . Bogotá, Colombia: Cinemateca Distrital. \}

[10] En lengua Embera hombres blancos o no indígenas.
[11]
Tomado
de:
http://www.

proimagenescolombia.com/secciones/cine colombiano/peliculas_colombianas/pelicula plantilla.php?id_pelicula $=613$

[12] Artículo 66. Ley de Víctimas y Restitución de Tierras, 2011.

[13] Artículo 66. Ley de Víctimas y Restitución de Tierras, 2011.

[14] Alberto Burgos Herrera. (2000). La música parrandera paisa. Medellín: Editorial Lealon.

[15] Este medio de comunicación sigue siendo el más eficiente a pesar de la llegada de nuevas tecnologías como la televisión y en algunas zonas específicas la telefonía.

[16] Imagen 1: Ibanafarag [Leonardo Morales]. (2012, Junio 18). Embera Chami. Recuperado de https://www.youtube.com/ watch? $\mathrm{v}=\mathrm{saP} 1 \mathrm{mp}-\mathrm{md} 4 \mathrm{c}$

[17] Imagen 1: Ibanafarag [Leonardo Morales]. (2012, Junio 18). Embera Chami. Recuperado de https://www.youtube.com/ watch? $\mathrm{v}=\mathrm{saP} 1 \mathrm{mp}-\mathrm{md} 4 \mathrm{c}$

[18] Imagen 2: Bidika [Alejandro Ardila]. (2009, Octubre 26). Padachuma. Recuperado de https://www.youtube.com/ watch? $\mathrm{v}=3 \mathrm{La} 208 \mathrm{a} 0 \mathrm{~g} 7$

[19] Los colores de los vestidos por lo regular varían del verde, puesto que la idea es resaltar en medio de la selva y no ser confundidos con el entorno.

[20] Georges Didi-Huberman. (2014). Pueblos Expuestos, Pueblos Figurantes. Argentina: Ediciones Manantial.

[21] Vivienda tradicional construida de madera у раја.

[22] Bidika [Alejandro Ardila]. (2011, diciembre 25). Homenaje al maestro Virgilio. Recuperado de https://www.youtube.com/ watch?v=egBCudBenhw

[23] Emberá (también conocido como Chocó) es un continuo dialectal hablado por 100.000 personas en el noroeste de Colombia y el sureste de Panamá. Pertenece a la familia de la lengua Choco. 
[24] Plátano dominico

[25] Curandero tradicional

[26] Espíritus de la selva

[27]Anna María Guasch.(2003). LOSESTUDIOS

VISUALES EN EL SIGLO 21. Un estado de la cuestión. Murcia, España: CENDEAC.

[28] Pablo Mora Calderón. (2013). Nuestras

miradas. Bogotá, Colombia: Fundación

Friedrich Ebert Stiftung.

Para citar este artículo

Cruz Sandoval, C. (2019). El video Indígena en la comunidad Emberá Chamí.

Nuevas estéticas y sistemas de circulación. Revista Luciérnaga Comunicación. Vol. 11, N22. Pp. 95 - 111. Doi: https://doi.org/10.33571/revistaluciernaga.v11n22a4

OJS. https://revistas.elpoli.edu.co/index.php/luc/issue/archive 